\title{
Analisis Pemasaran Sapi di Kabupaten Batubara
}

\section{The Analysis of Cattle Marketing in Batubara District}

\author{
Fahrizal Irham1), Hasnudi'2), Rasmulia Sembiring3), Tumpal H.S. Siregar4]
}

1) Program Studi Magister Agribisnis, Pascasarjana, Universitas Medan Area

2) Departemen Peternakan, Fakultas Pertanian, Universitas Sumatera Utara, Indonesia

3)Jurusan Manajemen, Fakultas Ekonomi dan Bisnis, Universitas Methodist, Indonesia

4) Magister Agribisnis, Pascasarjana, Universitas Medan Area, Indonesia

\begin{abstract}
Abstrak
Penelitian ini bertujuan untuk mengidentifikasi dan menganalisis saluran pemasaran, margin pemasaran, tingkat bagian peternak, efisiensi pemasaran dan strategi pemasaran sapi di Kabupaten Batubara. Penelitian ini dilaksanakan pada bulan Mei - Juni 2017. Lokasi penelitian dipilih secara purposive sampling dan dilakukan di 3 (tiga) kecamatan yaitu Kecamatan Lima Puluh, Sei Suka, dan Medang Deras. Responden penelitian diambil secara classified random sampling yaitu sebanyak 85 orang peternak sapi, dan sampel pedagang dipilih secara snowball ball sampling yaitu sebanyak 11 orang pedagang pengumpul lokal dan 2 orang pedagang besar. Analisis data dilakukan secara deskriptif kuantitatif. Hasil penelitian menunjukkan bahwa terdapat 4 saluran yang terbentuk dari lembaga pemasaran yaitu saluran pemasaran I (peternak-agen pengumpul lokal-pedagang besar-jagal), saluran pemasaran II (peternak - agen pengumpul lokal-konsumen), saluran pemasaran III (peternak-agen pengumpul lokal-pedagang luar daerah) dan saluran pemasaran IV (peternak-konsumen/jagal). Margin pemasaran tertinggi terdapat pada saluran I dan yang paling rendah terdapat pada saluran pemasaran IV. Bagian yang diterima peternak tertinggi terjadi pada saluran pemasaran IV sebesar $100 \%$ dan yang paling rendah terjadi pada saluran pemasaran I. Saluran pemasaran IV merupakan saluran yang paling efisien dilihat dari hasil penghitungan indeks efisiensi.

Kata kunci: Saluran pemasaran, Margin pemasaran, Bagian Peternak, Efisiensi Pemasaran.
\end{abstract}

\begin{abstract}
This study aims to identify and analyze marketing channels, marketing margins, farmer share levels, marketing efficiency and cattle marketing strategies in Batubara Regency. This research was conducted in May - June 2017. The research location was selected by purposive sampling and carried out in 3 (three) districts, Lima Puluh, Sei Suka, and Medang Deras Districts. The research respondents were taken by classified random sampling as many as 85 cattle farmers, and the sample of traders selected by snowball ball sampling were 11 local collectors and 2 large traders. Data analysis was performed descriptively quantitative. The results showed that there were 4 channels formed from marketing institutions namely marketing channel I (breeder-local collecting agent-big-slaughterer), marketing channel II (breeder - local-consumer collecting agent), marketing channel III (breeder-collecting agent local-traders outside the region) and marketing channels IV (breeder-consumer / butcher). The highest marketing margin is in channel I and the lowest is in marketing channel IV. The highest portion received by farmers occurred in marketing channel IV by $100 \%$ and the lowest occurred in marketing channel I. Marketing channel IV was the most efficient channel seen from the calculation of the efficiency index.

Keywords: Marketing channels, Marketing margins, Breeder Section, Marketing Efficiency.
\end{abstract}

How to Cite: Irham, F., Hasnudi, R. Sembiring, \& T. H. S. Siregar. (2019). Analisis Pemasaran Sapi di Kabupaten Batubara. Jurnal Ilmiah Magister Agribisnis, 1(2) 2019: 120-128,

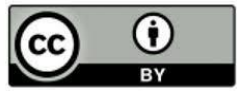




\section{PENDAHULUAN}

Kabupaten Batubara terletak di tepi pantai Selat Malaka, sekitar $175 \mathrm{~km}$ selatan ibu kota Medan. Sesuai dengan letak geografisnya, Kabupaten Batubara yang merupakan salah satu Kabupaten yang ada di Provinsi Sumatera Utara mempunyai keunggulan sebagai daerah agraris dan maritim yang kaya akan sumber daya alam pertanian dan peternakan. Bila dikaji dari perkembangan populasi sapi 6 tahun terakhir, Kabupaten Batubara mengalami peningkatan setiap tahunnya. Dengan meningkatnya populasi sapi membuat Kabupaten Batubara menjadi salah satu sentra peternakan sapi di Provinsi Sumatera Utara.

Sektor peternakan sapi di Kabupaten Batubara selama ini menunjukkan hal yang positif, hal ini dapat tecapai sebagai hasil kerja keras peternak sapi bersama pemerintah Kabupaten Batubara. Populasi sapi terbesar terdapat di Kecamatan Lima Puluh, kemudian dengan populasi menegah di Kecamatan Sei Suka dan yang paling sedikit terdapat di Kecamatan Medang Deras.

Sapi Peranakan Ongole (PO) merupakan jenis sapi yang paling banyak terdapat di peternak yang ada di Kabupaten Batubara, karena dianggap lebih mampu beradaptasi dengan baik di lingkungan lokal. Selain keunggulan tersebut, peternak di Kabupaten Batubara juga mendapat bantuan bibit sapi jenis tersebut dari Dinas Peternakan dan Perkebunan Kabupaten Batubara, melalui beberapa kelompok peternak yang tersebar di Kabupaten Batubara. Selain pemberian bibit sapi, dalam hal peningkatan populasi sapi di wilayahnya, Pemerintahan Kabupaten Batubara juga mempunyai program peningkatan populasi ternak dengan cara inseminasi buatan dan juga kawin alami.

Penerapan teknologi tepat guna ini juga dilakukan di Pemerintah Kabupaten Batubara, khususnya untuk pembuatan pakan berkualitas untuk peningkatan populasi sapi. Di samping itu pemanfaatan limbah pertanian dan perkebunan untuk dijadikan pakan ternak, seperti jerami, bekatul padi, pelepah sawit, dan solid membran. Pemerintah juga menggalakkan penanaman rumput gajah di sekitar areal peternakan dengan tujuan untuk menjamin ketersediaan terhadap pakan segar bagi ternak (Dinas Peternakan dan Perkebunan Kabupaten Batubara, 2017).

Program peningkatan populasi beriringan dengan upaya pengendalian penyakit sehingga tingkat kematian ternak berkurang. Antisipasinya melalui vaksinasi, rehabilitasi dan monitoring. Dinas Peternakan juga menjamin ketersediaan bahan pangan bersumber dari hewan yang sehat dan aman, dengan membimbing pemotong dan pedagang untuk memenuhi persyaratan-persyaratan yang ada sebelumnya (Bappeda Kabupaten Batubara, 2017).

Sejalan dengan meningkatnya pendapatan dan kesadaran gizi masyarakat serta jumlah penduduk maka permintaan daging sapi dari tahun ke tahun terus meningkat. Kabupaten Batubara memiliki potensi peternakan yang masih dapat ditumbuh kembangkan. Sub sektor peternakan juga mempunyai peranan strategis dalam menunjang pembangunan Kabupaten Batubara.

Dalam rangka menunjang pemasaran sapi yang semakin meningkat populasinya, Pemerintah Kabupaten Batubara juga membangun pasar hewan di Kecamatan Talawi, 
dimana pasar hewan ini diharapkan menjadi sentra transaksi jual beli ternak yang resmi di Batubara.

Dalam faktanya sub sistem agribisnis hilir terutama pemasaran merupakan bagian dari sub sistem terlemah, padahal potensi keuntungan pada pemasaran cukup tinggi (Siregar, 2006). Persoalan mengenai harga dan kualitas sapi masih menjadi masalah yang tidak dapat dipisahkan dalam pemasaran sapi di Kabupaten Batubara. Selain itu dengan hanya ada satu pasar hewan ditambah jauhnya jangkauan oleh beberapa daerah peternak ke pasar hewan yang terdapat di Kecamatan Talawi mengarah terbentuknya suatu rantai pemasaran yang cukup panjang, karena dengan adanya pedagang perantara tentunya menambah kompleksitas dalam upaya perbaikan harga jual dan kualitas sapi.

Banyak dari peternak yang menjual sapi mereka melalui pedagang pengumpul (agen) yang berada di wilayah Kabupaten Batubara, sedikit dari peternak yang menjual langsung hasil ternaknya ke konsumen akhir. Pada sistem pemasaran sapi, pendapatan peternak akan meningkat dengan semakin efesiennya pemasaran sapi. Untuk itu peternak sebagai pelaku utama agribisnis peternakan harus di berdayakan dalam seluruh sub sistem dari sistem agribisnis terutama pemasaran, sangat diperlukan kebijakan sebagai upaya terobosan guna meningkatkan peran dan posisi tawar peternak pada sistem agribisnis sapi.

Persoalan kelancaran pemasaran sapi di kabupaten Batubara sangat bergantung pada kualitas sapi yang dihasilkan peternak sebagai produsen dan tentu saja upaya penyempurnaan kinerja lembaga-lembaga pemasaran dan sistem pemasaran sapi itu sendiri sehingga akan meningkatkan pendapatan dan tingkat kesejahteraan peternak sapi. Dengan meningkatnya pendapatan peternak akan sekaligus memberikan motivasi peternak untuk meningkatkan skala usahanya yang pada akhirnya akan meningkatkan populasi, produksi dan produktifitas.

\section{METODE PENELITIAN}

Penelitian dilakukan di Kabupaten Batubara. Penentuan tempat penelitian dengan alasan daerah-daerah tersebut secara berurutan merupakan populasi ternak sapi yang paling tinggi, menengah, dan terendah. Bentuk penelitian yang digunakan yaitu deskriptif kuantitatif memakai metode survey, data sekunder diperoleh dari Dinas Peternakan dan Perkebunan Kabupaten Batubara dengan jumlah sampel penelitian sebanyak 85 orang peternak. Teknik analisis data yang digunakan dengan mentabulasikan secara sederhana dengan menghitung besar volume penjualan, biaya pemasaran, margin pemasaran dan share margin untuk setiap saluran pemasaran.

\section{HASIL DAN PEMBAHASAN}

Peternakan Sapi di Kabupaten Batubara

Kondisi peternakan sapi di Kabupaten Batubara cukup berkembang. Kondisi ini dapat dilihat dari jumlah populasi ternak dan perkembangan populasi ternak setiap tahun. Perkembangan populasi sapi di Kabupaten Batubara dapat dilihat di tabel di bawah ini: 
Tabel 1. Populasi Ternak Sapi di Kabupaten Batubara Menurut Kecamatan, 2011 - 2016 (Ekor)

\begin{tabular}{clrrrrrr}
\hline No & Kecamatan & $\mathbf{2 0 1 1}$ & $\mathbf{2 0 1 2}$ & $\mathbf{2 0 1 3}$ & $\mathbf{2 0 1 4}$ & $\mathbf{2 0 1 5}$ & $\mathbf{2 0 1 6}$ \\
\hline $\mathbf{1}$ & Medang Deras & 433 & 221 & 281 & 295 & 293 & 503 \\
$\mathbf{2}$ & Sei Suka & 4.607 & 3.012 & 3.055 & 3.218 & 3.264 & 9.145 \\
$\mathbf{3}$ & Air Putih & 421 & 351 & 434 & 456 & 429 & 520 \\
$\mathbf{4}$ & Lima Puluh & 14.209 & 17.919 & 18.023 & 18.930 & 20.487 & 18.594 \\
$\mathbf{5}$ & Talawi & 3.347 & 3.284 & 3.200 & 3.360 & 3.419 & 3848 \\
$\mathbf{6}$ & Sei Balai & 2.093 & 1.959 & 1.921 & 2.017 & 2.053 & 4.772 \\
$\mathbf{7}$ & Tanjung Tiram & 703 & 852 & 871 & 815 & 945 & 1.054 \\
\hline & Jumlah & $\mathbf{2 5 . 8 1 3}$ & $\mathbf{2 7 . 5 9 8}$ & $\mathbf{2 7 . 7 8 5}$ & $\mathbf{2 9 . 0 9 1}$ & $\mathbf{3 0 . 8 9 0}$ & $\mathbf{3 8 . 4 3 6}$ \\
\hline
\end{tabular}

Sumber: Dinas Peternakan Kabupaten Batubara, 2017

Dari table 1. diketahui bahwa jumlah populasi ternak sapi terbesar menurut kecamatan pada tahun 2016 berada di Kecamatan Lima Puluh sebesar 18.594 ekor sapi atau 48,37 \% dari total populasi sapi di Kabupaten Batubara, kemudian dengan populasi menengah terdapat di Kecamatan Sei Suka dengan jumlah populasi sebesar 9.145 ekor sapi atau sebesar 23,79 \% dari total seluruh populasi sapi di Kabupaten Batubara dan populasi sapi terkecil berada di Kecamatan Medang Deras dengan jumlah populasi sebesar 503 ekor sapi atau hanya sebesar 1,3\% dari total seluruh populasi sapi di Kabupaten Batubara.

\section{Saluran Pemasaran Sapi di Kabupaten Batubara}

Berdasarkan hasil penelitian saluran pemasaran sapi di Kabupaten Batubara pada dasarnya terdiri dari 4 (empat) saluran, tetapi saluran pemasaran sapi di Kabupaten Batubara dapat berubah sesuai dengan permintaan di waktu-waktu tertentu seperti pada saat memasuki hari lebaran dan lebaran haji, dengan kata lain saluran pemasaran sapi di Kabupaten Batubara dapat berubah- ubah mengikuti keadaan pasar.

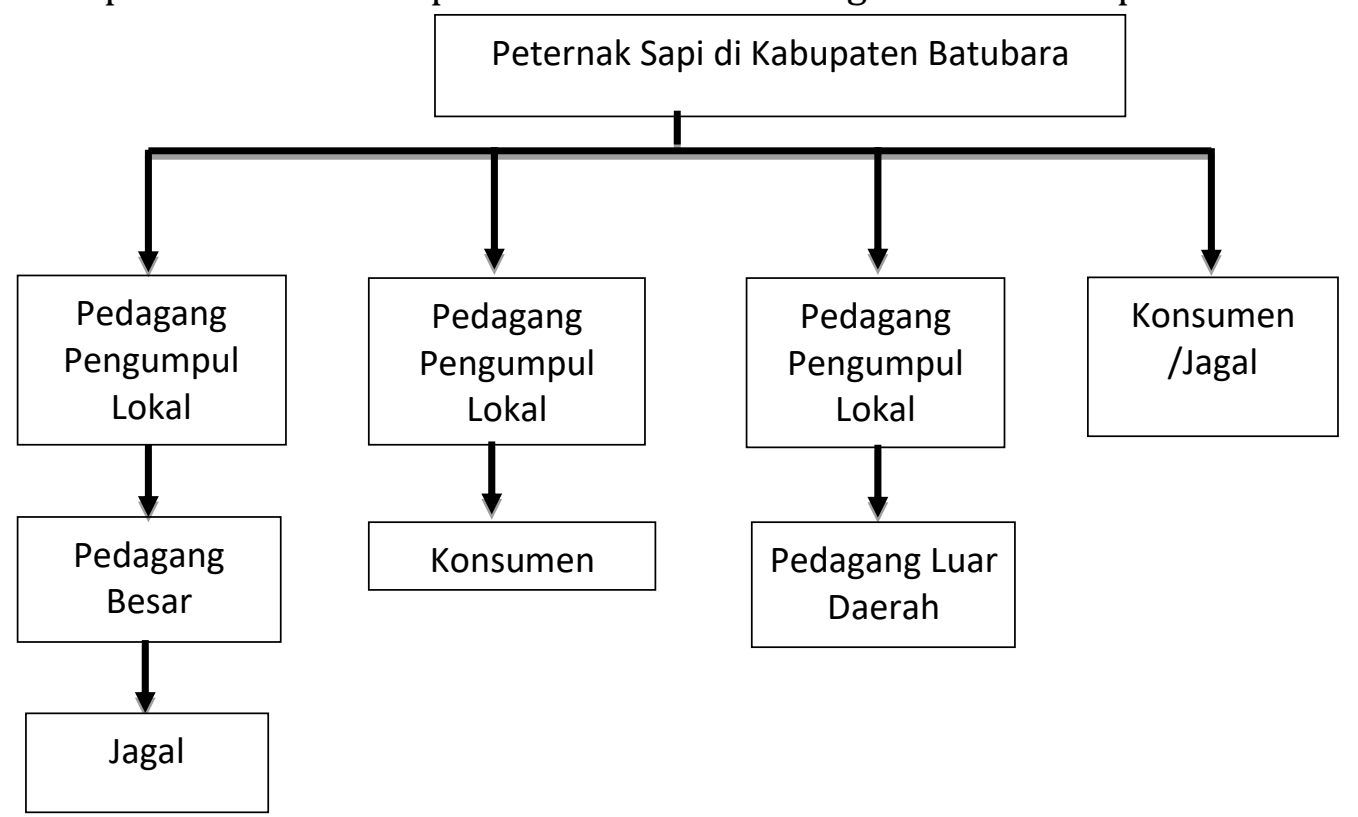

Gambar 1. Tataniaga Sapi di Kabupaten Batubara Pada 4 Tipe Saluran Pemasaran Keterangan :

Menyatakan hubungan. 
Lembaga pemasaran sapi di Kabupaten Batubara meliputi peternak, pedagang pengumpul (agen) lokal, pedagang besar, jagal dan pedagang luar Kabupaten. Sistem pemasaran sapi dilakukan hanya dengan taksiran yaitu dengan melihat penampilan sapi dan memperkirakan berat badan sapi.

\section{Harga Sapi Pada Setiap Saluran Pemasaran di Kabupaten Batubara}

Tabel 2 menunjukkan bahwa harga sapi pada masing-masing saluran pemasaran di Kabupaten Batubara sebagai berikut:

Tabel 2. Harga Pada 4 Saluran Pemasaran Sapi di Kabupaten Batubara

\begin{tabular}{|c|c|c|c|c|c|}
\hline $\begin{array}{l}\text { Saluran } \\
\text { Pemasaran }\end{array}$ & $\begin{array}{l}\text { Peternak } \\
\text { (Rata-Rata } \\
\text { Harga Jual } \\
\text { Rp/Ekor) }\end{array}$ & $\begin{array}{l}\text { Agen Lokal } \\
\text { (Rata-Rata } \\
\text { Harga Beli } \\
\text { Rp/Ekor) }\end{array}$ & $\begin{array}{c}\text { Pedagang Besar } \\
\text { (Rata-Rata } \\
\text { Harga Beli } \\
\text { Rp/Ekor) }\end{array}$ & $\begin{array}{c}\text { Pedagang Luar } \\
\text { Kota (Rata-Rata } \\
\text { Harga Beli } \\
\text { Rp/Ekor) }\end{array}$ & $\begin{array}{c}\text { Konsumen / } \\
\text { Jagal (Rata-Rata } \\
\text { Harga Beli } \\
\text { Rp/Ekor) }\end{array}$ \\
\hline Saluran 1 & 14.548 .166 & 14.548 .166 & 15.783 .333 & & 16.916 .667 \\
\hline Saluran 2 & 9.652 .083 & 9.652 .083 & & & 10.593 .750 \\
\hline Saluran 3 & 14.765 .333 & 14.765 .333 & & 16.625 .000 & \\
\hline Saluran 4 & 15.318.333 & & & & 15.318 .333 \\
\hline
\end{tabular}

Sumber: Data Primer (diolah), 2017

\section{Biaya Pemasaran Sapi di Kabupaten Batubara}

Tabel 3. Biaya Pemasaran Sapi Pada Saluran 1 di Kabupaten Batubara

\begin{tabular}{lrr}
\hline \multicolumn{1}{c}{$\begin{array}{c}\text { Lembaga dan Komponen Biaya } \\
\text { Pemasaran }\end{array}$} & $\begin{array}{c}\text { Biaya Pemasaran } \\
\text { (Rp/Ekor) }\end{array}$ & $\begin{array}{c}\text { Nilai } \\
\text { (Rp/Ekor) }\end{array}$ \\
\hline $\begin{array}{l}\text { 1. Harga jual peternak } \\
\text { 2. Pedagang Pengumpul Lokal } \\
\text { a. Harga beli dari peternak }\end{array}$ & 14.548 .166 \\
b. Biaya pemasaran & 14.548 .166 & \\
c. Harga jual ke pedagang besar & 169.000 & \\
d. Marjin bersih pedagang pengumpul & 1.066 .167 & \\
3. Pedagang Besar & $15,783.333$ \\
$\begin{array}{l}\text { a. Harga beli dari pedagang pengumpul } \\
\text { b. Biaya pemasaran }\end{array}$ & $15,783.333$ & \\
c. Harga jual ke jagal & 127.500 & \\
d. Marjin bersih pedagang besar & & 16.916 .667 \\
\hline
\end{tabular}

Sumber: Data Primer (diolah), 2017

Tabel 3 menunjukkan pada saluran pemasaran 1 mempunyai lembaga pemasaran yaitu: peternak, pedagang pengumpul lokal, pedagang besar dan jagal. Margin yang diperoleh lembaga pemasaran yaitu pedagang pengumpul lokal sebesar Rp.1.066.167/ekor sapi dan pedagang besar kabupaten sebesar Rp.1.005.834/ekor sapi. Hal ini sesuai dengan teori pemasaran menurut Rahim dan Hastuti (2007), yang 
mendasari bahwa semakin panjang saluran pemasaran maka margin dan biaya pemasaran juga akan semakin besar. Harga rata-rata sapi di tingkat peternak sebesar Rp.14.548.166/ekor jauh lebih kecil dari harga rata-rata yang di bayarkan oleh jagal sebesar Rp.16.916.667/ekor. Oleh karena itu secara tidak langsung biaya pemasaran dibebankan kepada peternak sebagai produsen sapi dengan jalan menerima pembelian yang rendah. Dalam saluran ini pedagang besar menerima keuntungan terbesar karena merupakan pengendali harga sapi.

Tabel 4. Biaya Pemasaran Sapi Pada Saluran 2 di Kabupaten Batubara

\begin{tabular}{lcc}
\hline \multicolumn{1}{c}{$\begin{array}{c}\text { Lembaga dan Komponen Biaya } \\
\text { Pemasaran }\end{array}$} & $\begin{array}{c}\text { Biaya Pemasaran } \\
\text { (Rp/Ekor) }\end{array}$ & $\begin{array}{c}\text { Nilai } \\
\text { (Rp/Ekor) }\end{array}$ \\
\hline 1. Harga jual peternak & & 9.652 .083 \\
2. Pedagang Pengumpul Lokal & & \\
a. Harga beli dari peternak & 9.652 .083 & \\
b. Biaya pemasaran & 162.500 & 10.593 .750 \\
c. Harga jual ke konsumen & & \\
d. Marjin bersih pedagang pengumpul & 779.167 & \\
\hline
\end{tabular}

Sumber: Data Primer (diolah), 2017

Tabel 5. Biaya Pemasaran Sapi Pada Saluran 3 di Kabupaten Batubara

\begin{tabular}{lrr}
\hline \multicolumn{1}{c}{$\begin{array}{c}\text { Lembaga dan Komponen Biaya } \\
\text { Pemasaran }\end{array}$} & $\begin{array}{c}\text { Biaya Pemasaran } \\
\text { (Rp/Ekor) }\end{array}$ & $\begin{array}{r}\text { Nilai } \\
\text { (Rp/Ekor) }\end{array}$ \\
\hline $\begin{array}{l}\text { 1. Harga jual peternak } \\
\text { 2. Pedagang Pengumpul Lokal }\end{array}$ & 14.765 .333 \\
$\begin{array}{l}\text { a. Harga beli dari peternak } \\
\text { b. Biaya pemasaran }\end{array}$ & 14.765 .333 & \\
c. Harga jual ke pedagang luar kota & 530.000 & \\
d. Marjin bersih pedagang pengumpul & & 16.625 .000 \\
\hline
\end{tabular}

Sumber: Data primer (diolah), 2017.

Pada saluran 4 biaya pemasaran sapi tidak dihitung, dikarenakan pada saluran ini peternak langsung menjual sapi kepada konsumen ataupun jagal. Disini konsumen ataupun jagal langsung datang ke peternak sehingga biaya restribusi dan biaya transportasi semua di tanggung oleh konsumen ataupun jagal yang membeli sapi (berdasarkan persepsi dari peternak).

\section{Margin Pemasaran}

Tabel 6 menunjukkan bahwa margin pemasaran yang paling besar adalah pada saluran 1 sebesar Rp.2.368.501 dengan tujuan akhir jagal. Sedangkan margin pemasaran yang paling kecil adalah pada saluran 4 sebesar Rp.0. Dari segi margin pemasaran dapat disimpulkan bahwa saluran 4 merupakan saluran pemasaran sapi yang paling efesien di daerah penelitian. Hal ini dikatakan efesien karena peternak mendapatkan harga yang paling tinggi dibandingkan tiga saluran lainnya. Menurut Daniel (2002) semakin banyak 
lembaga tataniaga yang terlibat, semakin panjang rantai tataniaga dan semakin besar biaya pemasaran komoditi tersebut.

Tabel 6. Margin Pemasaran Pada 4 Saluran Pemasaran Sapi di Kabupaten Batubara.

\begin{tabular}{lrrrr}
\hline Harga (Tingkat) & \multicolumn{1}{c}{ Saluran 1 } & \multicolumn{1}{c}{ Saluran 2 } & \multicolumn{1}{c}{ Saluran 3 } & \multicolumn{1}{c}{ Saluran 4 } \\
\hline Peternak & 14.548 .166 & 9.652 .083 & 14.765 .333 & 15.318 .333 \\
Konsumen Akhir & 16.916 .667 & 10.593 .750 & 16.625 .000 & 15.318 .333 \\
Margin Pemasaran & 2.368 .501 & 941.667 & 1.859 .667 & 0 \\
Net Margin Pemasaran & 2.072 .001 & 779.167 & 1.329 .667 & 0 \\
\hline
\end{tabular}

Sumber: Data Primer (diolah), 2017

\section{Distribusi Net Margin (Margin Bersih) Pemasaran}

Distribusi net margin terbesar berada pada saluran 3, dimana pedagang pengumpul lokal membeli sapi langsung dari peternak dan pedagang pengumpul lokal mendapatkan net margin sebesar Rp.1.329.667/ekor.

Tabel 7. Distribusi Net Margin Pemasaran Sapi Pada 4 Saluran Pemasaran di Kabupaten Batubara tahun 2017.

\begin{tabular}{|c|c|c|c|c|}
\hline No & $\begin{array}{c}\text { Lembaga/Saluran } \\
\text { Pemasaran }\end{array}$ & $\begin{array}{l}\text { Net Marjin } \\
\text { Rp/Ekor }\end{array}$ & $\begin{array}{c}\text { Distribusi Net } \\
\text { Marjin (\%) }\end{array}$ & $\begin{array}{c}\text { Harga Tingkat } \\
\text { Akhir }\end{array}$ \\
\hline \multirow[t]{4}{*}{1} & Lembaga/Saluran 1 & & & \\
\hline & P. Pengumpul Lokal & 1.066 .167 & 45,01 & 16.916 .667 \\
\hline & P. Besar & 1.005 .834 & 42,47 & \\
\hline & Jumlah & 2.072 .001 & 87,48 & \\
\hline \multirow[t]{3}{*}{2} & Lembaga/Saluran 2 & & & \\
\hline & P. Pengumpul Lokal & 779.167 & 85,02 & 10.593 .750 \\
\hline & Jumlah & 779.167 & 85,02 & \\
\hline \multirow[t]{3}{*}{3} & Lembaga/Saluran 3 & & & \\
\hline & P. Pengumpul Lokal & 1.329 .667 & 71,5 & 16.625 .000 \\
\hline & Jumlah & 1.329 .667 & 71,5 & \\
\hline \multirow[t]{2}{*}{4} & Lembaga/Saluran 4 & & & \\
\hline & Peternak & 0 & 0 & 15.318 .333 \\
\hline
\end{tabular}

Sumber: Data Primer (diolah), 2017

\section{Share Margin (Bagian harga yang diterima peternak)}

Saluran 4 merupakan saluran yang memberikan share paling besar yaitu 100\%, dikarenakan pada saluran ini peternak langsung menjual sapi hasil usaha ternaknya kepada konsumen tidak melalui lembaga pemasaran lain sebagai perantara. Secara teoritis biasanya saluran pemasaran yang mempunyai rantai pemasaran atau tataniaga paling pendek disukai oleh peternak untuk memasarkan hasil ternaknya, tetapi di daerah penelitian kasusnya berbeda dimana saluran pemasaran dengan rantai paling panjang yang banyak digunakan peternak. 
Tabel 8. Bagian (share) yang Diterima Peternak Sapi Pada 4 Saluran Pemasaran di Daerah Penelitian

\begin{tabular}{ccccc}
\hline \multirow{2}{*}{ Komoditi Sapi } & \multicolumn{3}{c}{ Share } \\
\cline { 2 - 4 } & Saluran 1 & Saluran 2 & Saluran 3 & Saluran 4 \\
\hline Peternak & $85,99 \%$ & $91,11 \%$ & $88,81 \%$ & $100 \%$ \\
\hline
\end{tabular}

Sumber: Data Primer (diolah), 2017

\section{Price Spread}

Dalam penelitian ini harga sapi yang diterima peternak akan dibandingkan dengan harga sapi yang diterima lembaga pemasaran akhir dari sistem pemasaran sapi di daerah penelitian. Perbandingan antara harga yang diterima peternak dengan harga yang diterima lembaga pemasaran akhir untuk semua saluran memiliki perbedaan yang signifikan.

Tabel 9. Price Spread Pada 4 Saluran Pemasaran Sapi di Daerah Penelitian Tahun 2017.

\begin{tabular}{lrrrr}
\hline Komoditi Ternak & \multicolumn{1}{c}{ Saluran 1 } & \multicolumn{1}{c}{ Saluran 2 } & \multicolumn{1}{c}{ Saluran 3 } & \multicolumn{1}{c}{ Saluran 4 } \\
\hline Harga Diterima Peternak & 14.548 .166 & 9.652 .083 & 14.765 .333 & 15.318 .333 \\
Harga Konsumen Akhir & 16.916 .667 & 10.593 .750 & 16.625 .000 & 15.318 .333 \\
Price Spread & & & & \\
\hline
\end{tabular}

Sumber: Data Primer (diolah), 2017

\section{Analisis Efisiensi Pemasaran}

Agar sapi hasil produksi peternak di daerah penelitian sampai ke konsumen akhir pada setiap saluran pemasaran yang ada di daerah penelitian telah melewati berbagai lembaga pemasaran. Harga di tingkat akhir lembaga pemasaran serta efisiensi pemasaran dari setiap saluran ditentukan oleh panjangnya rantai pemasaran yang tercipta. Setiap lembaga pemasaran yang dilalui memiliki biaya pemasaran dan marginnya masing-masing.

Tabel 10. Efisensi Pemasaran Pada 4 Saluran Pemasaran di Daerah Penelitian Tahun 2017

\begin{tabular}{cccc}
\hline Saluran & Biaya Pemasaran (Rp) & $\begin{array}{c}\text { Nilai Harga Tingkat } \\
\text { Akhir (Rp) }\end{array}$ & $\begin{array}{c}\text { Efisiensi Pemasaran } \\
(\%)\end{array}$ \\
\hline 1 & 296.500 & 16.916 .667 & 1,75 \\
2 & 162.500 & 10.593 .750 & 1,53 \\
3 & 530.000 & 16.625 .000 & 3,18 \\
4 & 0 & 15.318 .333 & 0 \\
\hline
\end{tabular}

Sumber: Data Primer (diolah), 2017 
Irham, F., Hasnudi, R. Sembiring, \& T. H. S. Siregar. Analisis Pemasaran Sapi di Kabupaten Batubara,

\section{SIMPULAN}

Terdapat 4 (empat) saluran pemasaran sapi yang ada di Kabupaten Batubara. Terdapat perbedaan biaya pemasaran, margin pemasaran, share margin dan price spread pada antar saluran pemasaran. Tingkat efisiensi setiap saluaran pemasaran berbeda-beda.

Kepada peternak, hendaknya menggunakan saluran pemasaran keempat yaitu peternak langsung menjual sapi ke konsumen karena saluran pemasaran ini merupakan saluran pemasaran yang paling efesien yang ada di Kabupaten Batubara untuk dapat meningkatkan pendapatan yang diperoleh peternak. Peternak harus merubah pola fikir dari pola menafsirkan berat sapi menggunakan taksiran semata ke perhitungan sistem yang telah dikembangkan oleh ahli, sehingga peternak tidak merasa ditipu oleh agen dalam menentukan harga jual sapi mereka. Pemerintah Kabupaten Batubara harus membuat suatu standar skema harga jual sapi di Kabupaten Batubara sehingga peternak dan agen memiliki suatu patokan harga jual sapi yang lebih akurat.

\section{DAFTAR PUSTAKA}

Daniel, M. (2002). Pengantar Ekonomi Pertanian. Bumi Aksara. Jakarta.

Dinas Peternakan dan Perkebunan Kabupaten Batubara, 2017.

Dolan, Robert J. (1981). “Models of Competitio: A Review of Theory and Empirical Evidence," in Ben M. Enis and Kenneth J. Roeing, (eds.), Review of Marketing (Chicago: American Marketing Association).

Flud, Leonard M. (1992). The New Competitor Intelligence: The Complete Resource for Finding, Analyzing, and Using Information about Your Competitors (New York: John Wiley, 1995); John A. Czepiel, Competitive Marketing Strategy (Upper Saddle River, NJ: Prentice Hall).

Gultom, H.L.T. (1996). Tata Niaga Pertanian. USU Press, Medan.

Juneke, M., et al. (2016). Analisis Pemasaran Buah Pepaya di Desa Matungkas Kecamatan Dimembe Kabupaten Minahasa Utara. Jurnal Agri-Sosioekonomi Universitas Sam Ratulangi, Makassar.

Koeswara, S, (1995). Pemasaran Industri. Djambatan. Jakarta.

Kotler, Philip. (2005). Manajemen Pemasaran Jilid I. PT. Indeks Kelompok Gramedia Jakarta.

Kotler, Philip dan Kevin L. Keller. (2007). Manajemen Pemasaran Edisi Kedua Belas Jilid I, Indeks.

Kusuma, Tonni., et al. (2013). Strategi Pemasaran Sapi Potong di CV Septia Anugerah Jakarta. Jurnal Departemen Teknologi Industri Pertanian, Fakultas Teknologi Pertanian, Institut Pertanian Bogor, Bogor.

Laksana, Fajar. (2008). Manajemen Pemasaran Edisi Pertama, Yogyakarta, Graha Ilmu.

Mubyarto. (1997). Pengantar Ekonomi Pertanian. LP3ES, Jakarta.

Porter, Michael E. (1980). Competitive Strategy. The free Press, New York.

Pearce dan Robinson. (2011). Manajemen Strategis: Formulasi, Implementasi, dan Pengendalian. Jakarta: Penerbit Salemba Empat.

Rahadi, F dan Hartono, R. (2003). Agribisnis Peternakan. Penebar Swadaya. Jakarta.

Rahim, A. (2007). Ekonomi Pertanian. Penebar Swadaya. Jakarta.

Rangkuti, Efrihadi. (2016). "Analisis Kelayakan Usaha Pembuatan Ikan Asin Di Kelurahan Belawan Bahari Kecamatan Medan Belawan Kota Medan." Tesis Universitas Medan Area. Medan.

Soekarwati. (2002). Prinsip Dasar Manajemen Pemasaran Hasil-hasil Pertanian. Raja Grafindo Persada, Jakarta.

Suarda. (2009). Saluran Pemasaran Sapi Potong di Sulawesi Selatan. Jurnal Sains \& Teknologi. Vol IX (2), Agustus 2009. 